\title{
Comparing the Stratigraphy of the Last Glaciation in the Loess Plateav and the Indian and Pacific Oceans
}

Grain size and susceptibility profiles from Wupu (approximately $250 \mathrm{~km}$ southeast of Yulin) and Yannchang (approximately 330 $\mathrm{km}$ south of Yulin) are compared with benthic foraminifera $\delta^{18} \mathrm{O}$ records from the Maldives area of the tropical Indian Ocean (Bassinot et al., 1994), and ODP 677 in the eastern equatorial Pacific Ocean (Shackleton et al., 1990; Shackleton, 1996). Grain size and magnetic susceptibility profiles from the Loess Plateau are proxies for variations in winter and summer monsoon intensity, respectively. Loess grain size records show a high degree of coherency with the SPECMAP record (Imbrie et al., 1984) of ice volume variations (Ding et al., 1994). Hence, increases in ice volume may intensify the Siberian-Mongolian high pressure system by down stream cooling of mid-latitude air, leading to stronger winter monsoon winds and a larger overall median grain size of loess (Ding et al., 1994). Further, the Mass Accumulation Rate $(\mathrm{MAR}=$ linear sedimentation rate times dry bulk density) of loess is a function of aridity (Rea, 1994) and the availability of loess at its source. The benthic foraminifera $\delta^{18} \mathrm{O}$ record is commonly regarded as a proxy for ice volume variations since very little temperature and salinity fractionation should occur in the deepest parts of the oceans, and assuming that species variations are minimal. The $\delta^{18} \mathrm{O}$ record from MD900963 is particularly well expressed owing to a local salinity effect, most likely controlled by changes in mon-

Our purpose is to contrast proxy climate records from the Loess Plateau with the oceanic records, and search for similarities and soon intensity (Bassinot et al., 1994).

differences in the response of the proxy records to climate change. In particular we compare the proxy response of MIS 2 (loess subhorizon L1-1) and MIS 4 (subhorizon L1-5). We do not attempt to compare the amplitude of responses; nevertheless, if the proxy records from the Loess Plateau are responding to variations in ice volume then we should see some similarities in the profiles. However, differences observed between terrestrial and oceanic proxy climatic signals may be due to different responses of these proxy signals to internal and external climate forcing mechanisms, sampling variations, and proxy tool limitations.

Fig. 11 demonstrates the first order correlations of the last interglacial-glacial cycle using the MIS $5 / 6$ transition as the datum (e.g. 'Termination II' of Broecker and Van Donk, 1970). This transition is regarded as being a reasonably synchronous global event. In figure 11 we use depth scales from each location and attempt to avoid the influence of age models that assume constant sedimentation rates between control points. While it may be true that sedimentation rates are fairly constant in geologic time, the assumption of linear sedimentation rates in high resolution studies (e.g. 1000 years per sample or less) is tenuous. For example, in the Loess Plateau loess sedimentation rates are higher during cold periods than in warmer times (Rutter et al., 1995).

Subhorizon L1-1 is bordered by the Holocene soil (S0) above and a weak paleosol (L13) below. The grain size profile within loess subhorizon L1-1 shows a lower median grain size in the bottom half of the subhorizon

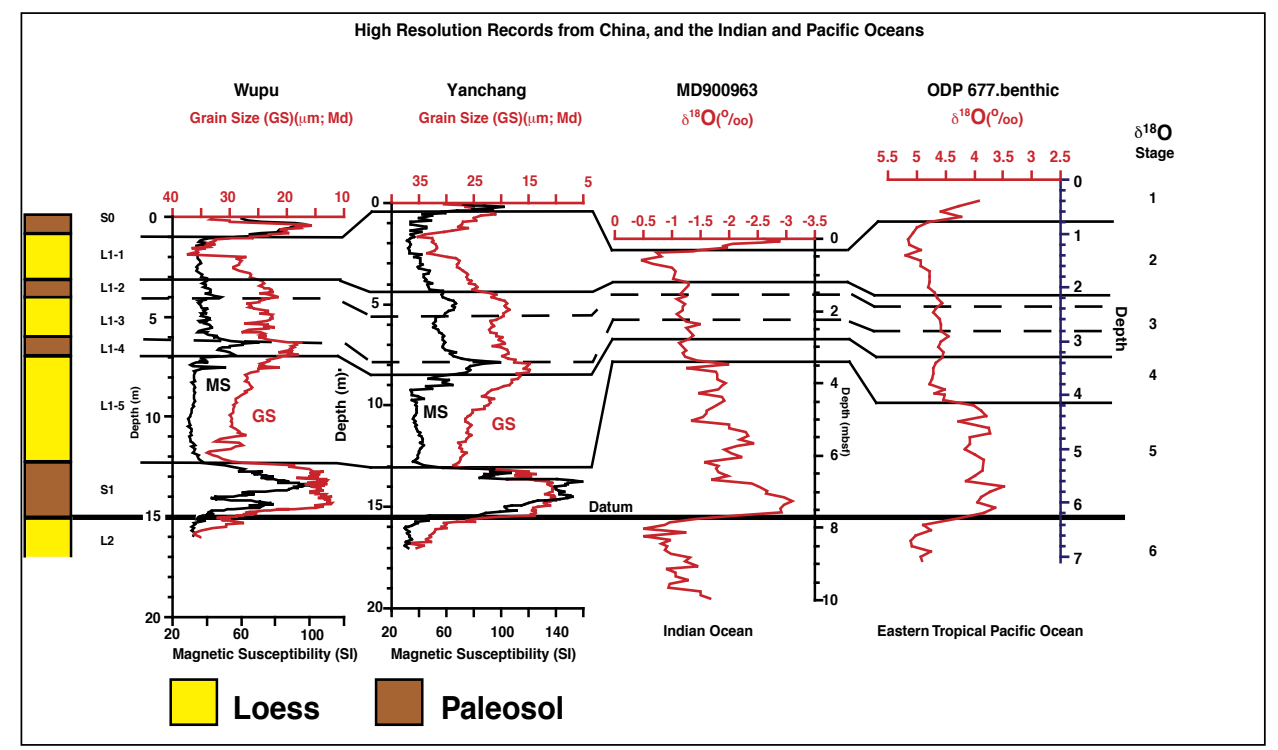

Fig. 11: Stratigraphy of the last Glaciation (Marine Isotope Stages 2, 3 and 4). Samples at $5 \mathrm{~cm}$ intervals in the loess-paleosol sections. with an abrupt transition to a higher median grain size in the upper part of the subhorizon. This profile is similar to the ocean $\delta^{18} \mathrm{O}$ profiles indicating a high degree of coherency between median grain size (wind strength) and ice volume variations during MIS2. Note that the base of MIS 2 in oceanic records is more commonly picked above our interpretation of the MIS $2 / 3$ boundary, and represents a revision of the original MIS 2 boundary.

Loess subhorizon L1-5 (MIS 4) in the Wupu and Yanchang sections are about 5.3 and 4.8 meters thick, respectively, while loess subhorizon L1-1 (MIS 2) is about 2.1 and 3.0 meters thick, respectively. We presently do not know the dry bulk densities of L1-1 and L1-5 and cannot calculate a MAR. However, using SPECMAP (Imbrie et al., 1984) ages for the top of MIS 2.0 (12 ka). 3.0 (24 ka), 4.0 (59 $\mathrm{ka})$ and $5.0(71 \mathrm{ka})$ the accumulation rates of L1-1 and L1-5 at Wupu are 0.175 meters/ka and 0.44 meters $/ \mathrm{ka}$, while the accumulation rates at Yanchang are 0.25 meters / $k a$ and 0.4 meters / ka, respectively. Hence, loess accumulations rates are higher and ice volumes lower during MIS 4 than during MIS 2. This is apparently at odds with recent work (Shackleton et al., 1995), suggesting that dust accumulation in China is highly coherent with the $\delta^{18} \mathrm{O}$ global ice volume record. Shackleton et al. (1995), however, were dealing with glacial to interglacial variations over the past 2.5-3.0 million years as opposed to our loess record of the last glaciation (L1).

In conclusion, we are refining the stratigraphy of oceanic and loess records to improve understanding of climate change and the relationship between the global ice volumes and the loess record. Our revision of the base of MIS 2 provides a more coherent record of the relationship between variations in loess grain size (e.g. wind strength) and ice volumes during MIS 2. Additionally, we surmise that the higher accumulation rates during L1-5 may be related to the east European glacial record, where older glaciations on the Russian Plain were more extensive (Velich$\mathrm{ko}, 1990$ ). If our conjecture is correct, then accumulation rates during MIS 4 would be related to regional ice volumes rather than global ice volume.

Charles D. Rokosh, Nat W. Rutter and E.C. Little Department of Earth \& Atmospheric Sciences, University of Alberta, T6G 2E3 Edmonton, Canada drokosh@gpu.srv.ualberta.ca

nat.rutter@ualberta.ca

Zhongl Ding and T. SUn

Institute of Geology, C.A.S, P.O.Box 9825,

100029 Beijing, China

dingz|@midwest.com.cn 